\title{
A Healthy Retirement Program for Thai government teachers: a quasi- experimental and comparison groups study
}

\author{
Numporn Insin, Chanuantong Tanasugarn and Sarunya Benjakul \\ Faculty of Public Health, Mahidol University Rajvithi Campus, Bangkok, Thailand
}

\begin{abstract}
Purpose - The purpose of this study is to evaluate the Healthy Retirement Program's effectiveness toward skills improvement and evaluate changes in subjective health.

Design/methodology/approach - A quasi-experimental, pre and posttest of the comparison groups was conducted. Teachers who were going to retire within one year were recruited into the experimental $(n=47)$ and the comparison groups $(n=43)$. Questionnaires were administered at baseline, posttest and at the 6-months follow-up. An independent $t$-test and Mann-Whitney $U$ test were applied to determine the differences in outcomes between groups.

Findings - The results revealed different effects regarding teachers' health status. In those who had no chronic disease, the experimental group had higher skills to understand health information at posttest and at follow-up ( $p=0.036,0.028$ ). Skills to apply health information was also greater at follow-up $(p=0.042)$. Among those suffering from a chronic disease, skills to access and apply health information were significantly higher in the experimental group than that of the comparison at follow-up $(p=0.011,0.046)$. Greater perceived health of the experimental group was also indicated $(p=0.032)$.

Originality/value - While the health conditions of teachers at the preretirement period are inconsistent, healthy lifestyle management after retirement is a crucial skill for retirement adjustment. Supporting teachers to be health literate should be included in the retirement planning program which emphasizes preretiree's ability to understand and take control of their health.
\end{abstract}

Keywords Healthy retirement, Retirement planning, Healthy lifestyles, Retirement adjustment,

Healthy aging, Thailand

Paper type Research paper

\section{Introduction}

Thailand's increasing aging population is set to become a serious economic challenge due to the budget required to support the needs of the growing elderly population. The Thai government has provided health care benefits for all Thai civil servants for their entire life, as a result of which the government budget for the health care costs of Thai retired civil servants have increased considerably in the past decade [1]. This reflects that the government has financially supported a high ratio of unhealthy retirees.

(C) Numporn Insin, Chanuantong Tanasugarn and Sarunya Benjakul. Published in Journal of Health Research. Published by Emerald Publishing Limited. This article is published under the Creative Commons Attribution (CC BY 4.0) licence. Anyone may reproduce, distribute, translate and create derivative works of this article (for both commercial and non-commercial purposes), subject to full attribution to the original publication and authors. The full terms of this licence may be seen at http:// creativecommons.org/licences/by/4.0/legalcode

The authors are thankful to Mrs Niratree Raksapakdee, Mr Korn Anupansuebsai and Mrs Sumrit Saisorn for their support on data collection. Special thanks are extended to SF-12 License Prequalification from Optum Office of Grants and Scholarly Research.

Funding: This research received no specific grant or agency funding.
Retirement Program for Thai teachers 
JHR

36,1

128

In recent years, the number of Thai retired teachers in the government sector is rapidly increasing. A recent report showed that more than 110,000 teachers are due to retire in 2019-2022 [2]. This situation requires an evidence-based response, but the existing action is still minimal[2]. After retiring, teachers face several changes (e.g. a decreasing income, reduced social interaction and altered daily life activities) that affect their well-being in later life [3].

Currently, the Thai government provides support to retired teachers with their retirementrelated problems [4] including decreasing income served by pension and lump sum allowance. Furthermore, health care benefits cover the costs of disease treatments and health check-ups. In addition, retired teachers were recruited to be contract teachers, and this supported their income and perceptions of their retirement status [5].

Considering the global development, the World Health Organization published the first World Report on Ageing and Health which outlines the framework to promote healthy aging [6]. The term healthy aging was redefined as a process of developing and maintaining the functional ability that enables well-being in old age. All sectors in the public can contribute to achieving the same goal of maximizing the functional ability of older persons. Focusing on Thailand, the first National Long-term Plan for Older Persons was established in 1986 [7]. Until now, the second National Plan for Older Adults mainly emphasized social welfare, a free health care program, and long-term saving and social engagement [7]. However, the concept of healthy aging has not been adopted into practice.

Retirement adjustment leads some retirees to develop unhealthy lifestyles after retiring [8]. Accordingly, a higher incidence of health problems that need long-term care was reported [9-12]. These reflect that retirees require the ability to manage healthy lifestyles after retirement.

Adequate retirement planning influences better retirement outcomes [13-15]. Thus, retirement planning programs were conducted and reported the benefits to raise perceptions of retirement-related changes and to manage the retirement goal [16-20]. However, no existing program emphasized healthy lifestyle management for those who are imminently due to retire.

The present study developed a Healthy Retirement Program (HRP) which emphasized healthy lifestyle management for Thai government teachers. The HRP was evaluated toward the improvement of perceived changes regarding retirement and skills to manage a healthy lifestyle after retirement. This study also determined whether the HRP had positive effects on retirement well-being through the changes of perceived health and life satisfaction. The findings can guide the necessity of healthy retirement in a retirement planning program.

\section{Methodology}

\section{Research design and setting}

A quasi-experimental, pre- and posttest for the comparison groups was conducted in Sakon Nakhon (SN) at one of eighteen regional education centers located in this province. Sakon Nakhon Primary Educational Service Area (SN-PESA) was divided into three PESAs. SN-PESA1 and SN-PESA2 were randomly assigned to be the experimental and the comparison groups.

\section{Population and samples}

Three hundred and twenty six eligible participants were selected from teachers due to retire at the mandatory age in the fiscal year 2016. They were working in primary schools under SN-PESA1 $(N=162)$ and SN-PESA2 $(N=164)$. The study population was identified using inclusion and exclusion criteria. Teachers were recruited if they were able to participate in the eight-week program and complete data collections at baseline, posttest and six months after retirement. They were excluded if they reported any life-threatening medical condition or planned to relocate from the research setting within one year after retirement. Eventually, 
a total of 310 teachers comprising 150 in the experimental, and 160 in the comparison groups met these criteria. Then, PESA invited those teachers to enroll in the study by official letter. After receiving research information, 265 samples of which 141 were in the experimental and 124 in the comparison groups voluntarily participated (94 and $77.5 \%$ of the study population).

\section{The HRP development}

Relevant theories and concepts. The current knowledge identified multilevel factors influencing retirement planning and retirement well-being [21]. The HRP applied three relevant theories to address at the individual, interpersonal and organizational levels. Selfefficacy enhancement strategies guided by social cognitive theory were included in the program's activities [22]. Meanwhile, the HRP applied four supportive types to enhance the functions of social support among teachers' relationships that could promote healthy lifestyles after retirement [23]. In addition, the stage theory of organizational change was applied to encourage PESA to develop a new policy and practices that would contribute to healthy lifestyles for retirement planning [24].

The HRP components. The HRP aimed to improve perceived changes regarding retirement, and skills to manage healthy lifestyles after retirement. Three learning themes for preretired teachers were designed as an 11-session workshop. Firstly, "the changes and effects of retirement" was to understand retirement-related changes and their effects on health and well-being. Secondly, "life skills to manage healthy lifestyles after retirement" focused on decision-making to set retirement goals and create an actual retirement plan. Third, "heath skills to manage healthy lifestyles after retirement" was designed to interpret individual health status and to encourage control over individual health, for instance, exercise and diet in old age, brain exercise and seeking social groups.

Several learning strategies were applied in the HRP to enhance self-efficacy to manage healthy lifestyles after retirement. For example, retired seniors with different lifestyles were selected as role models in case studies. Training improved a set of skills to interpret physical and mental health examination results, and control over health, and Thai traditional medicine and massage. Verbal persuasion was provided by the researchers, implementors and a group of preretired teachers. Good emotional states of learning were created by relaxing activities. The workshops totaled eight sessions at eight weeks before retirement and were followed by three sessions at the eighth week.

Reinforcement to convince adopting or continuing retirement planning was provided through an eight-week implementation period via a social media group. Messages relevant to learning topics were provided two to three times per week to remind participants of learning or to give information. The group members included preretired teachers, administrators, staff members, health professionals and researchers. Group discussion and sharing topics were proposed, and members were allowed to share their ideas or experiences. Then, the members were prompted to give feedback to each other while the researchers and PESA's staff members provided feedback or answered any questions.

PESA's physical and social environment were the major influences of retirement planning for teachers. PESA's contexts i.e. policy, projects and services related to retirement, and PESA's resources including staff members, budget and annual plan were taken into account to design the activities for administrators and staff members. In order to change PESA's policy and practices to support teachers to manage healthy lifestyles after retirement, it was agreed that the PESA contributed to passing each stage of organizational changes [24] at two weeks prior to the implementation among preretired teachers. At the awareness stage: administrators and staff members were provided with the information of retirement-related changes and their effects and also given an idea of the HRP. At the adoption stage:

\author{
Healthy \\ Retirement \\ Program for \\ Thai teachers
}


JHR

36,1

130

brainstorming was performed to identify PESA resources and roles in providing support for teachers. At implementation stage: PESA's staff members developed an action plan of the HRP implementation while administrators monitored its progress. At institutional change stage: a lesson learned session aimed to identify PESA's resources needed in adopting the HRP into an annual plan.

Program feasibility was ensured by a group discussion of the HRP's topics, activities and evaluation with administrators and staff members of PESA and representative teachers. A top-down approach was properly applied for the HRP implementation. Then, the HRP was reviewed by experts and representative teachers. Finally, the HRP manual guide was created to ensure its reliability.

\section{Data collection}

A self-administered questionnaire was utilized at baseline and posttest. The baseline was done within one week before the HRP implementation. Meanwhile, the comparison group also received equivalent retirement information through leaflets and booklets. During the HRP implementation, two samples in the experimental group reported health problems and withdrew from the study. The overall adherence rate of the HRP was $98.6 \%$. However, only 119 samples in the experimental and 81 samples in the comparison completed a posttest questionnaire (drop-out rate were 15.6 and $34.7 \%$ ). Then, follow-up took place at six-months after retirement by mail-questionnaire. To prevent the weakness of high loss rates in the follow-up by mail-questionnaire, the researchers reminded participants to complete the questionnaire by phone at 7 and 14 days after post mail. After 30 days, unreturned questionnaires were recorded as "lost follow-up". Finally, 47 and 43 samples in the experimental and the comparison groups successfully completed three sets of data collection (the drop-out rate was 66.7 and $65.3 \%$, respectively).

The questionnaire measured different behavioral outcomes. The researchers had developed questions for four scales to measure perceived changes of retirement, life skills, perceived social support and perceived organizational support. Regarding the health skills and self-efficacy questions, the researchers modified these from previous studies [25, 26] while for the perceived health status and life satisfaction, the researchers applied the questionnaire developed by Jenkinson et al., Diener et al. and Maher et al. [27-29].

The questionnaire was reviewed for its content validity and revised by three experts of gerontology and health promotion research. Reliability was trialed among 30 preretired teachers in a nearby province SN and reported by Cronbach's alpha. The study's primary and secondary outcomes included:

Primary outcomes. Perceived changes of retirement. A perception of lifestyles and environmental changes after retirement and its effects on health and well-being measured by 18 items, a 5-rating scale ranging from "strongly disagree" to "strongly agree", for example, "How much do you perceive decreasing income after retirement? "Does retirement lead to more stress?” $(r=0.922)$

Life skills. Life skills comprised three dimensions (1) decision-making: the importance of healthy lifestyles management measured by 10 items, 5-rating scale ranged from "not at all important" to "very important". For example, "I am concerned about practicing more selfcare" "I am interested in volunteering" ( $r=0.952)$. (2) Planning: measured frequency of activities that were planned after retirement by 14 items with a 4-rating scale ranging from "plan not to do" to "plan to do regularly". For example, "I plan to do more exercise" "I plan to have an annual health check" $(r=0.939)$. (3) Seeking support: a frequency of activities which were planned if they needed help measured by 14 items in a, 4-rating scale ranged from "plan not to do" to "plan to do regularly". For example, "I will consult someone when I have a problem" "I will ask someone for information I need" $(r=0.930)$. 
Health skills. Health skills measured a perceived difficulty to access (5 items), understanding (5 items) and applying health information into everyday life (10 items) which was divided into three dimensions of health tasks including health care, disease prevention and health promotion. A 4-rating scale ranging from "very easy to do" to "very difficult to do" was modified from the European Health Literacy Survey Questionnaire [26] $(r=0.971)$. The six items of health care tasks were excluded in the samples who had no chronic disease (any diagnosed chronic health problem under long-term treatment and required taking regular medicine).

Secondary outcomes. Self-efficacy. Six items assessed perceived confidence to manage healthy lifestyles after retirement modified from a short form of the General Efficacy Scale [25]. The 4-rating scale ranged from "not at all true" to "exactly true" For example, "I can practice more self-care if I am concerned about my health condition" "I can do extra jobs for more income if my pension is not enough" $(r=0.901)$

Perceived social support. Ten items measured perceived support from friends and family to manage healthy lifestyles by a 5-rating scale ranged from "strongly disagree" to "strongly agree" For example, "My friends give me helpful information", "My family encourages me to be healthy" $(r=0.912)$.

Perceived organizational support. Perceived support from the PESA and school to manage healthy lifestyles measured by 10 items, 5-rating scale ranged from "strongly disagree" to "strongly agree" For example, "PESA has a policy of healthy retirement", "the school provides me with retirement information" $(r=0.964)$.

Perceived health. A standard 12-item Short Form Survey version2 (SF-12v2) [28] comprised physical and mental health dimensions $(r=0.807)$.

Life satisfaction. 10 items, 5-rating scale ranged from "strongly disagree" to "strongly agree" or "not at all satisfied" to "very satisfied" that was modified from the Satisfaction with Life Scale [27] and Australian Unity Personal Wellbeing Index [29] $(r=0.936)$.

\section{Data analysis}

Chi-square test, Fisher's exact test and the Mann-Whitney $U$ test determined baseline differences of general characteristics and the prior health status of those who completed all data collection $(n=90)$ and those who withdrew $(n=175)$. The statistics indicated no significant difference. The similarity of general characteristics and prior health status between the experimental $(n=47)$ and the comparison groups $(n=43)$ were ensured by chisquare test, Fisher's exact test and Mann-Whitney $U$ test. An independent $t$-test determined the differences between groups at posttest and six-month follow-up considering baseline or Mann-Whitney $U$ test if the normality assumption was violated. The changes within the group through three observations were determined by repeated measured ANOVA. Health skills were separately analyzed among the samples for those who had a chronic disease and took regular medicine, and those who had no chronic disease.

\section{Ethical consideration}

The study protocol was approved by the Ethical Review Committee for Human Research Faculty of Public Health, Mahidol University, Thailand (COA. No. MUPH 2016-092. Approval date June 30, 2016).

\section{Results}

Table 1 shows the general characteristics of the experimental and the comparison groups. There was no statistical difference between groups $(\phi>0.05)$. Tables $2-4$ present the differences of primary and secondary outcomes between groups and the changes within groups.

\section{Healthy Retirement Program for Thai teachers}


JHR

36,1

\begin{tabular}{|c|c|c|c|}
\hline \multirow[b]{2}{*}{ Variables } & \multicolumn{2}{|c|}{ Number $(\%)$} & \multirow[b]{2}{*}{$p$-value } \\
\hline & Experimental group $(n=47)$ & Comparison group $(n=43)$ & \\
\hline $\begin{array}{l}\text { Age (years) } \\
59 \\
60 \\
61 \\
\text { Mean, SD }\end{array}$ & $\begin{array}{c}2(4.3) \\
40(85.1) \\
5(10.6) \\
60.06,0.38\end{array}$ & $\begin{array}{c}1(2.3) \\
40(93.0) \\
2(4.7) \\
60.06,0.27\end{array}$ & $0.548^{1}$ \\
\hline $\begin{array}{l}\text { Sex } \\
\text { Male } \\
\text { Female }\end{array}$ & $\begin{array}{l}16(34.0) \\
31(66.0)\end{array}$ & $\begin{array}{l}18(41.9) \\
25(58.1)\end{array}$ & $0.516^{2}$ \\
\hline $\begin{array}{l}\text { Marital status } \\
\text { Married } \\
\text { Single/Widow/divorced }\end{array}$ & $\begin{array}{l}35(74.5) \\
12(25.5)\end{array}$ & $\begin{array}{r}37(86.0) \\
6(14.0)\end{array}$ & $0.196^{2}$ \\
\hline $\begin{array}{l}\text { Education } \\
\text { Bachelor degree or under } \\
\text { Master degree }\end{array}$ & $\begin{array}{l}35(74.5) \\
12(25.5)\end{array}$ & $\begin{array}{r}37(86.0) \\
6(14.0)\end{array}$ & $0.196^{2}$ \\
\hline $\begin{array}{l}\text { Perceived income adequacy } \\
\text { Adequate income and saving } \\
\text { Adequate income with no saving } \\
\text { Inadequate income with/with no debt }\end{array}$ & $\begin{array}{l}13(27.7) \\
17(36.15) \\
17(36.15)\end{array}$ & $\begin{array}{l}17(39.5) \\
15(34.9) \\
11(25.6)\end{array}$ & $0.413^{3}$ \\
\hline $\begin{array}{l}\text { Chronic disease } \\
\text { Yes } \\
\text { No }\end{array}$ & $\begin{array}{l}29(61.7) \\
18(38.3)\end{array}$ & $\begin{array}{l}24(55.8) \\
19(44.2)\end{array}$ & $0.669^{2}$ \\
\hline $\begin{array}{l}\text { Couple relationship satisfaction } \\
\text { Moderately to very satisfied } \\
\text { Completely satisfied } \\
\text { Not answered }\end{array}$ & $\begin{array}{r}6(12.8) \\
26(55.3) \\
15(31.9)\end{array}$ & $\begin{array}{r}10(23.3) \\
26(60.4) \\
7(16.3)\end{array}$ & $0.408^{2}$ \\
\hline $\begin{array}{l}\text { Family relationship satisfaction } \\
\text { Moderately to very satisfied } \\
\text { Completely satisfied }\end{array}$ & $\begin{array}{r}7(14.9) \\
40(85.1)\end{array}$ & $\begin{array}{l}13(30.2) \\
30(69.8)\end{array}$ & $0.127^{2}$ \\
\hline
\end{tabular}

Table 1.

Number and percentage of the samples categorized by general characteristics, prior health status, relationship satisfaction
Note(s): (1)p-value showed the statistical differences between groups determined by ${ }^{1}$ independent $t$-test, ${ }^{2}$ Fisher's exact test and ${ }^{3}$ Chi-square test

Regarding perceived changes, the experimental group had lower scores than the comparison group at posttest $(p=0.034)$. Within-group, the analysis revealed steady levels of perceived changes in the experimental group $(p=0.625)$ while the comparison group significantly increased over baseline and posttest and turned into baseline at follow-up $(\phi=0.023)$.

Life skills revealed that seeking support was significantly higher in the experimental compared to the comparison group at follow-up $(\phi=0.013)$. Across the study, decisionmaking and planning were steady in both experimental $(p=0.885$ and 0.605$)$ and comparison groups $(p=0.948$ and 0.657$)$.

The analysis and results of health skills were separately presented in those who had no chronic disease and those who had chronic disease and took regular medicine regarding their health tasks. In those who had no chronic disease, both groups were significantly different in understanding health information at posttest $(p=0.036)$ and at follow-up $(\phi=0.028)$. Moreover, the experimental group showed greater skill to apply health information than the comparison at follow-up $(\phi=0.042)$. For those who had a chronic disease, a significant difference was not indicated at posttest. At follow-up, significant differences between 


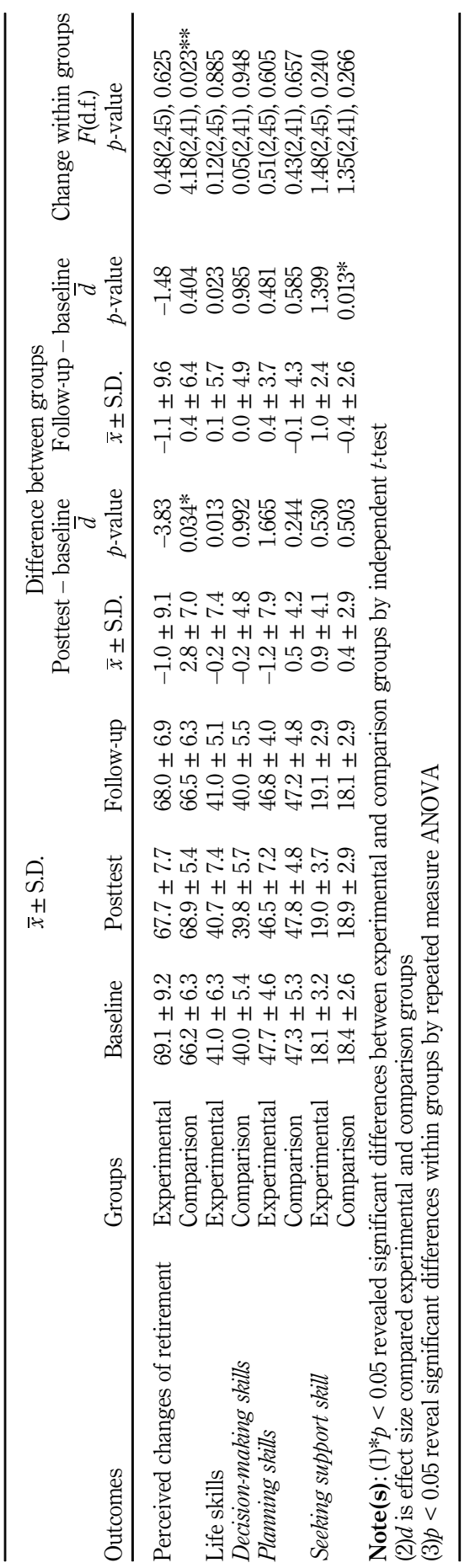

Healthy

Retirement Program for Thai teachers

133

Table 2.

Perceived changes after retirement and life skills improvement of HRP evaluation (experimental group $n=47$, comparison group $n=43$ ) 
JHR

134

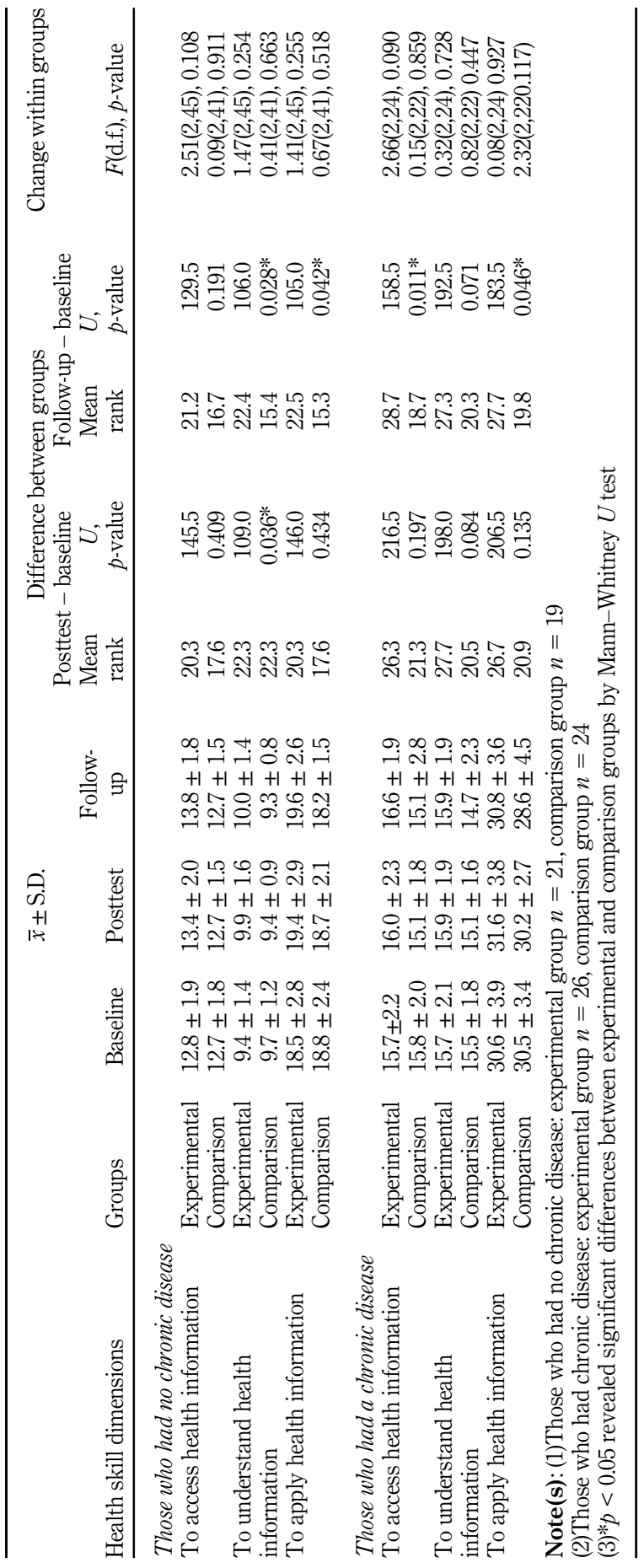

Table 3.

Health skill

improvement of HRP evaluation 


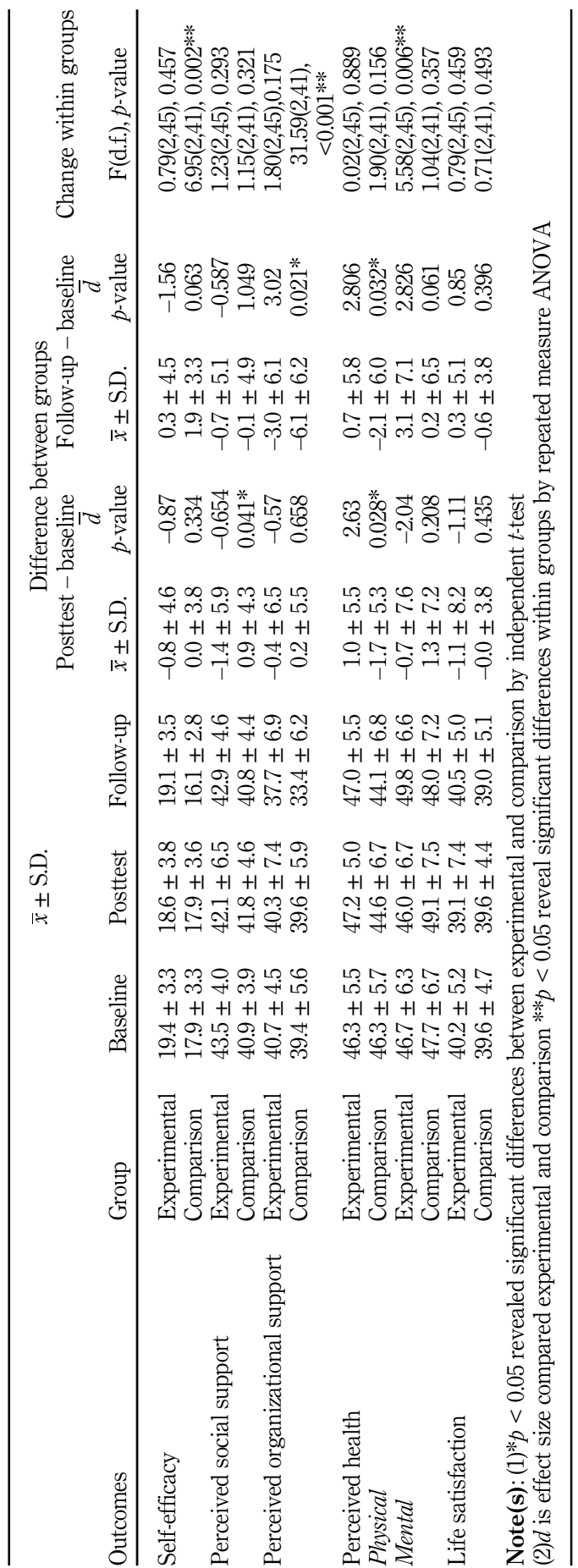

Healthy Retirement Program for Thai teachers

135

Table 4 Secondary outcomes of HRP evaluation (experimental $n=47$, comparison $n=43$ ) 
JHR

36,1

experimental and comparison groups were found in skills to access $(\phi=0.011)$ and to apply health information $(p=0.046)$.

Focusing on self-efficacy, there was no significant difference between groups at posttest and follow-up ( $p=0.334$ and 0.063). The experimental group had steady levels overtime $(p=0.457)$ while the decline was found in the comparison group $(\phi=0.002)$.

Perceived social support showed the differences between groups at posttest $(p=0.041)$. However, there was no significantly difference within groups.

Perceived organizational support in the experimental group was significantly greater than that of the comparison by the end of the study $(\phi=0.021)$. It had decreased over time in both groups but a significant decrease was found in the comparison group $(p<0.001)$.

In terms of health perception, the statistical analysis revealed significantly higher perceived physical health among the experimental group compared to the comparison at posttest and follow-up ( $p=0.028$ and 0.032). However, the difference between groups of perceived mental health was not found either at posttest or at follow-up $(\phi=0.208$ and 0.061$)$. Within the experimental group, perceived physical health was steady $(\phi=0.889)$ while perceived mental health had increased overtime $(p=0.006)$. Contrarily, the change was not indicated when comparing both physical and mental health $(p=0.848$ and 0.508).

Life satisfaction was not different between the two groups at posttest and follow-up $(p=0.435$ and 0.396$)$. Steady levels were observed over three observations.

\section{Discussion}

The main findings indicated that the HRP was able to improve skills to deal with life changes. The program took into account not only increasing the perception of changes but also enhancing the skills to manage the changes. Perceived changes had been transformed by life skills and health skills enhancement, then the level of perceived changes was decreased. These results supported the study by Glass and Flynn [30] that retirement planning was associated with decreasing anxiety regarding the retirement decision. Therefore, the experimental group perceived lower levels of changes after they were planning for retirement. In contrast, the comparison group revealed an increase in the level of the perceived change when it was closer to retirement similar to the study by Osuji [31]. These results can be explained by the Precaution Adoption Process Model [32] that persons move from the state of unawareness on health issues once they are making a decision and taking action for new behavior. Contrarily, in Aguilera's program that emphasized awareness of changes with no further skills development, the increasing awareness of changes was reported [16].

This current study had defined life skills in three dimensions as decision-making, planning and seeking support. Life skills in seeking support had significantly changed in the experimental group. This is similar to the study of Dube et al. [19] which showed significant changes in decision-making while this study reported significant changes in decision-making in seeking support. However, the total HRP activities which focused on three dimensions of life skills included only 5 of 15 hours of the workshop. This reflects that the activities for changing life skills may be insufficient and should be redesigned. Moreover, the comparison group had also received retirement information to support their decision-making as indicated in the research protocol. Therefore, the changes in the comparison group had also been identified.

Health skills enhancement had been included throughout the HRP training which has not been emphasized in any previous study. A recent mentorship program was carried out and reported health skills enhancement [20]. Thus, health skill enhancement activities may be significant for future HRP and should be measured accordingly. Moreover, future HRP should emphasize the difference in health status of preretirees since the results between healthy and sick teachers were different. 
The HRP encouraged the changes within PESA to provide organizational support to manage healthy lifestyles after retirement. Even though the level of organizational support had declined over time, the experimental group reported less decrease than the comparison group. Therefore, PESA plays a major role to support healthy retirement. The results showed that organizational support also continued postretirement. The HRP had developed the bonding of social relationships among preretired teachers, administrators and staff members of SN-PESA. Currently, only a few studies revealed the positive effects of organizational support on retirement adjustment $[33,34]$. Our results contribute to the literature that adopting healthy retirement into PESA's policy and practices are worthwhile and should be provided in a few years before retirement.

This present study measured the changes in health perception in two dimensions, however, our results revealed different changes between physical and mental health perceptions. Perceived physical health levels were higher in the experimental group while the comparison seemed to decrease over time. In this study, the experimental group had improved more accurate health perception regarding health examination results. This may be due to PESA policy and services that support teachers' learning to interpret and relate health examination results to physical, mental and environmental influences. Moreover, the HRP effectively increased levels of mental health perception. Our program emphasized psychological adjustment through the transition period from pre- to postretirement which is similar to Chan et al. [17].

There was no significant change in life satisfaction in this study while a few programs had reported significant changes [17, 20]. Previously, Atchley [3] proposed that retirement adjustments might be the changing pattern across the time of transition. The literature also supported that the significant change in life satisfaction was inconsistent at different points of time [35]. Therefore, longer follow-up periods at different points after retiring may be required to determine the changes in life satisfaction for the HRP.

Positive results of the HRP support the world strategy to promote healthy aging [6]. Growing older always requires adjustment through physical and psychological changes. Enabling people to learn, grow and make a decision are essential to maximizing the functional capacity of the elderly [6]. Thus, the HRP evaluation supports healthy aging practices that could promote better health in retirees.

\section{Conclusion}

The HRP could enhance personal ability to control changes after retirement and also influence changes in health perception after retirement. Therefore, PESA should adopt healthy retirement practices as part of their policy and practices as they are helpful to teachers who are approaching retirement.

\section{Limitations}

One of the limitations of this study was that the life skills component of the HRP may be insufficient due to the limit in implementation time. Life skills were defined as decisionmaking, planning and seeking support, but only 5 of 11 sessions emphasized these dimensions. Moreover, broader generalizability should be discussed because this study was conducted in a particular area of the country. Furthermore, the results may be biased due to a large number of samples who dropped out from the baseline assessment.

Conflict of interest: There is no conflict of interest.

\section{References}

1. Jindapol N, Kunupatham P, Theerasilp P, Kitikannakorn N. Crisis of health insurance under Thai civil servant medical benefit scheme (CSMBS). Srinagarind Med J. 2014; 29(2): 199-206. 
JHR

36,1

138
2. Office of the Civil Service Commission. Actions of measures to civil service administration and improvement (2014-2019): Thai civil servant teachers and educational personnel. [updated 2019 Feb 12; cited 2019 Aug 18]. Available from: https://www.ocsc.go.th/sites/default/files/attachment/ article/press_release_12_02_2526_praednchiiaecchngmaatrkaar_khpr._khruu.pdf.

3. Atchley RC. The sociology of retirement. Cambridge, MA: Schenkman Publishing; 1976.

4. Benchawan P. The preparation before the retirement. Princess of Naradhiwas University J Human and Soc Sci. 2015; 2(1): 82-92.

5. Tongying C. Teachers' problems, waiting for reform. [updated 2016 Dec; cite 2019 Dec 29]. Available from: https:/library2.parliament.go.th/ebook/content-issue/2559/hi2559-091.pdf.

6. Beard JR, Officer A, de Carvalho IA, Sadana R, Pot AM, Michel JP, et al. The world report on ageing and health: a policy framework for healthy ageing. Lancet. 2016; 387(10033): 2145-54. doi: 10.1016/S0140-6736(15)00516-4.

7. Jitapunkul S, Wivatvanit S. National policies and programs for the aging population in Thailand. Ageing Int. 2008; 33(1): 62-74. doi: 10.1007/s12126-009-9027-6.

8. Zantinge EM, van den Berg M, Smit HA, Picavet HS. Retirement and a healthy lifestyle: opportunity or pitfall? A narrative review of the literature. Eur J Public Health. 2014; 24(3): 433-9. doi: 10.1093/eurpub/ckt157.

9. Black DA, Wilson LA, O'Loughlin K, Noone J, Kendig H, Butcher J. Housing type, location of residence and health status in Australian baby boomers: results from the Australian Baby Boomer (ABBA) study. Australas J Ageing. 2015; 34(1): 43-6. doi: 10.1111/ajag.12119.

10. Bonsang E, Adam S, Perelman S. Does retirement affect cognitive functioning?. J Health Econ. 2012; 31(3): 490-501. doi: 10.1016/j.jhealeco.2012.03.005.

11. Godard M. Gaining weight through retirement? Results from the SHARE survey. J Health Econ. 2016; 45: 27-46. doi: 10.1016/j.jhealeco.2015.11.002.

12. Moon JR, Glymour MM, Subramanian SV, Avendano M, Kawachi I. Transition to retirement and risk of cardiovascular disease: prospective analysis of the US health and retirement study. Soc Sci Med. 2012; 75(3): 526-30. doi: 10.1016/j.socscimed.2012.04.004.

13. Noone JH, Stephens C, Alpass FM. Preretirement planning and well-being in later life: a prospective study. Res Aging. 2009; 31(3): 295-317. doi: 10.1177/0164027508330718.

14. Principi A, Smeaton D, Cahill K, Santini S, Barnes H, Socci M. What happens to retirement plans, and does this affect retirement satisfaction? Int J Aging Hum Dev. 2020; 90(2): 152-75. doi: 10.1177/ 0091415018796627.

15. Reitzes DC, Mutran EJ. The transition to retirement: stages and factors that influence retirement adjustment. Int J Aging Hum Dev. 2004; 59(1): 63-84. doi: 10.2190/nypp-rffp-5rfk-8eb8.

16. Aguilera M, Pérez J, Delgado D, Contreras M, Acosta M, Pozos BE. Educational preparation of older adults and their families for retirement. Adv Appl Sociol. 2013; 3(6): 237-45. doi: 10.4236/ aasoci.2013.36032.

17. Chan ML, Gustafsson L, Liddle J. An intervention to support professional driver retirement transition: results of a pilot study for older taxi drivers in Singapore. Brit J Occup Ther. 2015; 78(6): 391-400. doi: 10.1177/0308022614562400.

18. Cohen-Mansfield J, Regev I. Retirement preparation programs: an examination of retirement perceptions, self-mastery, and well-being. Res Social Work Prac. 2018; 28(4): 428-37. doi: 10.1177/ 1049731516645194.

19. Dube M, Lapierre S, Bouffard L, Alain M. Impact of a personal goals management program on the subjective well-being of young retirees. Eur Rev Appl Psychol. 2007; 57(3): 183-92. doi: 10.1016/j. erap.2005.04.004.

20. Ng SM, Leng L, Wang Q. Active interest mentorship for soon-to-retire people: a self-sustaining retirement preparation program. J Appl Gerontol. 2019; 38(3): 344-64. doi: 10.1177/ 0733464816687448. 
21. Hesketh B, Griffin B, Loh V. A future-oriented retirement transition adjustment framework. J Vocat Behav. 2011; 79(2): 303-14. doi: 10.1016/j.jvb.2011.03.008.

22. Bandura A. Health promotion by social cognitive means. Health Educ Behav. 2004; 31(2): 143-64. doi: 10.1177/1090198104263660.

23. House JS, Kahn RL, McLeod JD, Williams D. Measures and concepts of social support. In: Cohen S, Syme SL, editors. Social support and health. San Diego, CA: Academic Press; 1985. p. 83-108.

24. Butterfoss FD, Kegler MC, Francisco VT. Mobilizing organizations for health promotion: theories of organizational change. In: Glanz K, Rimer BK, Viswanath K, editors. Health behavior and health education: Theory, research, and practice. San Francisco, CA: Jossey-Bass; 2008. p. 335-61.

25. Romppel M, Herrmann-Lingen C, Wachter R, Edelmann F, Düngen HD, Pieske B, et al. A short form of the general self-efficacy scale (GSE-6): development, psychometric properties and validity in an intercultural non-clinical sample and a sample of patients at risk for heart failure. GMS Psychosoc Med. 2013; 10: Doc01. [cited 2016 Jul 17]. Available from: https://www.egms.de/static/ en/journals/psm/2013-10/psm000091.shtml.

26. Sorensen K, Van den Broucke S, Pelikan JM, Fullam J, Doyle G, Slonska Z, et al. Measuring health literacy in populations: illuminating the design and development process of the European Health Literacy Survey Questionnaire (HLS-EU-Q). BMC Public Health. 2013; 13: 948. doi: 10.1186/14712458-13-948.

27. Jenkinson C, Layte R, Jenkinson D, Lawrence K, Petersen S, Paice C, et al. A shorter form health survey: can the SF-12 replicate results from the SF-36 in longitudinal studies?. J Public Health Med. 1997; 19(2): 179-86.

28. Diener E, Emmons RA, Larsen RJ, Griffin S. The satisfaction with life scale. J Pers Assess. 1985; 49(1): 71-5.

29. Maher CA, Burton NW, van Uffelen JGZ, Brown WJ, Sprod JA, Olds TS. Changes in use of time, activity patterns, and health and wellbeing across retirement: design and methods of the life after work study. BMC Public Health. 2013; 13: 952. doi: 10.1186/1471-2458-13-952.

30. Glass JC, Flynn DK. Retirement needs and preparation of rural middle-aged persons. Educ Gerontol. 2000; 26(2): 109-34. doi: 10.1080/036012700267286.

31. Osuji CU. Teachers' perceptions and attitudes towards retirement in secondary schools: an analytical study. Int J Educ Res. 2014; 2(10): 355-70.

32. Weinstein ND, Sandman PM, Blalock SJ. The precaution adoption process model. In: Glanz K, Rimer BK, Viswanath K, editors. Health behavior and health education. 4th ed. San Francisco, CA: Jossey-Bass; 2008. p. 123-47.

33. Power ML, Hira TK. University-provided retirement planning support and retiree financial satisfaction during retirement: differences by gender, job classification, and planning behavior. Risk Manag Insur Rev. 2004; 7(2): 121-49. doi: 10.1111/j.1098-1616.2004.00041.x.

34. Wong JY, Earl JK. Towards an integrated model of individual, psychosocial, and organizational predictors of retirement adjustment. J Vocat Behav. 2009; 75(1): 1-13. doi: 10.1016/j.jvb.2008.12.010.

35. Zhu R, He X. How does women's life satisfaction respond to retirement? A two-stage analysis. Econ Lett. 2015; 137: 118-22. doi: 10.1016/j.econlet.2015.11.002.

\section{Corresponding author}

Chanuantong Tanasugarn can be contacted at: cttanasugarn@gmail.com

\section{Healthy Retirement Program for Thai teachers}

For instructions on how to order reprints of this article, please visit our website:

www.emeraldgrouppublishing.com/licensing/reprints.htm

Or contact us for further details: permissions@emeraldinsight.com 